\title{
sciendo
}

\section{The Fifth Metatarsal Bone Fracture In Athletes - Modalities of Treatment Related to Agility In Soccer Players}

\author{
by \\ Krzysztof Ficek1,2, Natalia Kędra1,3, Radostaw Skowronek ${ }^{1,3}$, Kamila Kluczniok ${ }^{1,3}$, \\ Magdalena Strózik ${ }^{1,2}$, Pawet Gwiazdoñ1,2,4, Grzegorz Hajduk ${ }^{2}$
}

\begin{abstract}
The $5^{\text {th }}$ metatarsal fracture is a common foot fracture which could exclude a player from competition for several months and significantly affect his or her career. This manuscript presents the treatment and rehabilitation of professional soccer players who had acute fractures of the 5 th metatarsal bone and a cannulated screw fixation. The main purpose of the analysis was to determine the minimum time necessary for a permanent return to the sport after a $5^{\text {th }}$ metatarsal fracture among professional soccer players. We followed the surgical and rehabilitation path of 21 professional soccer players from the Polish League (Ist and IInd divisions) who suffered from the $5^{\text {th }}$ metatarsal bone fracture. All players underwent standard percutaneous internal fixation with the use of cannulated screws. The total inability to play lasted for 9.2 ( \pm 1.86$)$ weeks among players treated only surgically $(n=10), 17.5( \pm 2.5)$ weeks in the conservative and later surgery group, excluding players with nonunion $(n=6)$, and $24.5( \pm 10.5)$ weeks for nonunion and switch treatment $(n=4)$ players. Prompt fracture stabilization surgery is recommended for athletes, enabling the implementation of an aggressive rehabilitation protocol as soon as possible. Early limb loading after surgery (from week 2) does not delay fracture healing or hinder the bone union, thus rehabilitation plays a crucial role in shortening the time of RTP (return to play) and is obligatory for each athlete who undergoes surgical treatment.
\end{abstract}

Key words: $5^{\text {th }}$ metatarsal fracture, athletes, intramedullary screw fixation, surgical treatment, rehabilitation.

\section{Introduction}

A fracture of the $5^{\text {th }}$ metatarsal bone is a specific problem of people who are permanently exposed to foot overload, including athletes. Fractures most often affect the base of the $5^{\text {th }}$ metatarsal and make for 40 to $75 \%$ of all foot fractures (Wang et al., 2020). The challenge often is the diagnosis itself, and most notably determining the correct type of the fracture. The literature concentrates on a few particular divisions of $5^{\text {th }}$ metatarsal fractures, the most popular of which seems to be the one proposed by Lawrence and Botte (1993). They differentiate between three types of fractures in the proximal part of the $5^{\text {th }}$ metatarsal bone: the tuberosity avulsion fracture, the Jones' fracture and the proximal diaphyseal stress fracture.

An avulsion fracture is an injury which occurs as a result of a rapid pull (usually the consequence of a sudden stop), a fracture emerging near the epiphysis of the bone along with a bone fragment detachment (Bowes and Buckley, 2016).

Stress fractures are the fallout of the accumulation of overloads which are not able to cause injury independently, but their multiplication leads to weakening of the bone tissue and in consequence, to its fracture. Stress fractures mainly affect the shaft of the bone (Mayer et al., 2014).

1 - Department of Physiotherapy, The Jerzy Kukuczka Academy of Physical Education, Katowice, Poland.

2 - Department of Science, Innovation and Development, Galen-Orthopaedics, Bieruń, Poland.

3 - Galen Rehabilitation, Bieruń, Poland.

4 - Department of Biopharmacy, Faculty of Pharmaceutical Sciences in Sosnowiec, Medical University of Silesia, Katowice, Poland 
Some discrepancies may be found due to diverging definitions of Jones fractures among different authors (Baumbach et al., 2017). Basically, this type of the fracture relates to an injury approximately $1.5 \mathrm{~cm}$ from bone tuberosity. In this zone both acute and stress fractures occur. The main reason of increased probability for a stress fracture in this area is its very limited blood supply. This could be the reason for reduced regenerative capacity of the bone tissue in this particular spot, which makes it difficult for microinjuries to regenerate. Restricted internal hip rotation, evidence of varus hindfoot alignment and field surface are subsequent factors which increase the risk of this fracture (Miyamori et al., 2019; Raikin et al., 2008; Saita et al., 2018). A low level of agility and motor control also play the key role in injury occurrence (Borghuis et al., 2008).

Soccer, due to its requirements of covering up to $12000 \mathrm{~m}$ in a game, frequent changes of direction and a multitude of various incidents (including fouls), seems to significantly increase the risk of foot injuries, including fractures among players (Boraczyński et al., 2020). The player's position on the field has to be considered in this regard (Thomson et al., 2018).

$X$-ray imaging is usually sufficient in the diagnosis of acute fractures. Problems can be caused by an incorrect diagnosis in the early stages of stress fractures, as they may not be clearly visible in X-ray imaging. MRI or skeletal scintigraphy are recommended in cases of lateral foot tenderness that worsen during exercise, which is one stress fracture symptom. Ultrasound examination is a cheaper and equally useful method of diagnosing stress fractures of the $5^{\text {th }}$ metatarsal bone. They can be all used both in the diagnostic process and monitoring of bone union (Battaglia et al., 2013).

The therapy depends on the type of injury and the physical activity of the patient. Minor fractures without bone dislocation are treated conservatively through temporary immobilization of the limb (6 to 10 weeks). A surgical intervention is recommended for more serious injuries, delayed union and non-union injuries (Miller et al., 2019; Pecina et al., 2011).

In sports medicine, the preferred treatment method of almost all fractures of the $5^{\text {th }}$ metatarsal bone is a surgical anastomosis, which results in a lower no-growth rate, shorter healing time, faster recovery and better clinical outcomes compared to conservative treatment (Bernstein et al., 2018).

The main purpose of the study was to determine the minimum amount of time necessary for a permanent return to the sport after a $5^{\text {th }}$ metatarsal fracture among professional soccer players.

\section{Methods}

A retrospective review of a database of professional soccer players from the Polish league who underwent surgical fixation of the $5^{\text {th }}$ metatarsal fracture between January 2014 and June 2019 in one orthopedic center was performed. A person having at least four training sessions a week for at least three years and who had played in the Polish soccer league (Ist and II ${ }^{\text {nd }}$ divisions) matches was considered a professional player. Information on age, sex, affected side, body mass index (BMI), and injury mechanisms was collected from the hospital's electronic database. Twenty-one soccer players who underwent surgical anastomosis of the $5^{\text {th }}$ metatarsal with a cannulated screw were included in the evaluation (Figure 1). The inclusion criteria were as follows: a professional Polish soccer player; age between 16 and 35 years; an acute, isolated and closed fracture of the $5^{\text {th }}$ metatarsal bone with a cannulated screw fixation, a followup over 12 months. The exclusion criteria were: age under 16 years; a follow-up less than 12 months; open or inveterate fractures; multiple fractures; incomplete chart or radiographic records. The characteristics of all participants are presented in Table 1 . The average age of players was $23( \pm 4)$ years, and their BMI was $23( \pm 1.2)$. All patients underwent standard percutaneous internal fixation with the use of a cannulated screw. Return to play (RTP) was determined on the basis of medical records and defined as a return to full training loads.

Standard percutaneous internal fixation with cannulated screws using spinal anesthesia was performed on all patients included in the study. The metatarsal base was approached through a dorsolateral incision followed by rhomboidal dissection. The section between the short and long fibular tendons was used to arrive at the bone area. The fixation was preceded by the Kirschner wire insertion into proximal tuberosity. 
A cannulated screw was fixated as soon as satisfactory positioning was achieved. The final objective was rigid fracture fixation with compression of the top. The postoperative protocol is presented in Table 2 and was similar for all patients.

Players were divided into two groups: Group A - only players who underwent surgical treatment $(\mathrm{n}=11)$, Group B - players who underwent conservative treatment first, and surgical treatment due to nonunion or refracture ( $\mathrm{n}=10$ ). Group $\mathrm{B}$ was divided into two subgroups: 1 - players with a nonunion bone and with modification of the treatment type $(n=4), 2$ players who returned to play after conservative treatment and had subsequent injury in the same bone $(n=6)$. The reinjury and nonunion bone cases were treated surgically using a cannulated screw.

\section{Statistical analysis}

The data analysis revealed that all data were normally distributed, with no further transformation required. A t-test was applied to compare time needed to RTP and total inability to play between groups. ANOVA was used to determine interactions of age, weight, height and BMI on their effect on the fracture risk. The level of significance was set at $p<0.05$ and all data were expressed as mean \pm SD.

\section{Results}

Midfielders were prominent in the group of risk for the fracture and comprised $48 \%$ of the examination group. A single patient from Group A suffered bone refracture. The cause of this injury was a foul by a player of the opposing team four weeks after RTP.

RTP after surgery was on average $9.5( \pm$ 2.3) weeks. Time between the surgery and RTP in group A was 0.4 weeks shorter than in group B (9.3 vs. 9.7 weeks; $p>0.05$ ) (Figure 2 ). The longest time need to RTP after surgical treatment was reported for players in subgroup 1 (10.8 \pm 3.1 weeks). Average time between RTP after conservative treatment and a refracture was 21.7 (min 6; max 52) weeks. A total time of inability to play was $10.3( \pm 2.8)$ weeks in Group A and 20.5 ( \pm 7.2$)$ weeks in Group B (Figure 3). The longest period of inability to play was in Group A, and concerned a player who suffered from a refracture (2 $\times 8$ weeks). In group $B$, the longest time of absence was reported in a player with a nonunion bone (40 weeks). The total time of inability to play in subgroup 1 was $17.8( \pm 2.4)$ weeks and 24.5 $( \pm 10.5)$ in subgroup 2 (Figure 4$)$. There were no statistical correlations between the fracture and age, weight, height.

\section{Discussion}

Lower limb injuries, including fractures of the $5^{\text {th }}$ metatarsal bone base, constitute a serious problem which can exclude a player from play for several months and significantly affect the athlete's career. Therefore, the likelihood of experiencing this particular fracture should be minimized, and if it occurs, appropriate steps should be taken as fast as possible to return to full training and performance. One should be aware that the selection of an approach to the injury treatment impacts the quality and time of returning to play. The risk of this exact injury may be related to the profile of the player, the position on the field and the type of training adequate for his/her field position. It has been shown that midfielders are more likely to have their metatarsal bone damaged, and the presented outcomes on this issue are consistent with the literature data (Thomson et al., 2018).

Surgical treatment of acute $5^{\text {th }}$ metatarsal bone fractures brings much better and faster results of recovery compared to conservative treatment (Bernstein et al., 2018; Hong et al., 2018; Japjec et al., 2015). Such a guideline is included in almost every fracture treatment protocol regarding athletes' convalescence (Japjec et al., 2015). The results presented in our paper confirm this observation. Although there were no significant differences in the time between surgery and RTP in the two groups, there was a more frequent refracture and nonunion bone in conservative treatment patients. About $30 \%$ of the study group who underwent conservative treatment in the past experienced a refracture. After surgical treatment, only one refracture was reported (due to an opponent's foul). A higher recurrence rate in the group with conservative treatment, especially athletes, has also been reported in other studies (Wu et al., 2018; Yates et al., 2015). Another problem is the nonunion bone rate, which ranges from 11 to $50 \%$ considering conservative treatment (Yates et al., 2015; Valkier et al., 2020). Our study presents four cases (19\%) of a 
nonunion bone after conservative treatment and no such a case after surgical treatment. The average time to RTP after a $5^{\text {th }}$ metatarsal fracture is approximately 9 weeks (Pecina et al., 2011), which was also confirmed in our study. Premature weight bearing on the limb can lead to delayed bone unification and other complications. Miller et al. (2019) showed that players who returned to the game after less than 8 weeks after the injury did not reach full bone union on the radiological imaging. In our analysis we included two cases with shorter RTP time, i.e., 6 weeks, however, no side effects occurred. The lack of statistical correlation between the fracture and age, weight and height may be due to the homogeneity of the group. All patients were professional players, similar in age and body measurements.

\begin{tabular}{|c|c|c|c|c|c|c|c|}
\hline \multicolumn{8}{|c|}{ Table 1} \\
\hline $\begin{array}{l}\text { patient } \\
\text { number }\end{array}$ & sex & age & BMI & position & $\begin{array}{l}\text { Injured } \\
\text { limb }\end{array}$ & $\begin{array}{l}\text { conservative } \\
\text { treatment in } \\
\text { the past }\end{array}$ & $\begin{array}{l}\text { time needed to return } \\
\text { to play after surgery } \\
\text { treatment (weeks) }\end{array}$ \\
\hline 1 & male & 22 & 22 & attacker & right & no & 6 \\
\hline 2 & male & 29 & 25 & attacker & left & yes & 6 \\
\hline 3 & male & 27 & 24 & attacker & right & yes & 16 \\
\hline 4 & male & 21 & 23 & attacker & right & yes & 12 \\
\hline 5 & male & 21 & 23 & midfielder & right & no & 8 \\
\hline 6 & male & 22 & 23 & midfielder & right & yes & 10 \\
\hline 7 & male & 27 & 24 & midfielder & right & yes & 10 \\
\hline 8 & male & 18 & 24 & midfielder & left & no & 8 \\
\hline 9 & male & 19 & 24 & midfielder & left & yes & 11 \\
\hline 10 & male & 17 & 20 & midfielder & left & yes & 8 \\
\hline 11 & male & 28 & 22 & midfielder & right & no & 9 \\
\hline 12 & male & 25 & 26 & midfielder & right & yes & 8 \\
\hline 13 & male & 25 & 22 & midfielder & left & no & 10 \\
\hline 14 & male & 22 & 24 & midfielder & right & no & 8 \\
\hline 15 & male & 34 & 24 & defender & left & no & 12 \\
\hline 16 & male & 20 & 25 & defender & right & no & 10 \\
\hline 17 & male & 22 & 23 & defender & left & yes & 10 \\
\hline 18 & male & 23 & 22 & goalkeeper & right & no & 8 \\
\hline 19 & male & 19 & 24 & indeterminate & right & no & 11 \\
\hline 20 & male & 27 & 24 & indeterminate & right & no & 10 \\
\hline 21 & male & 21 & 23 & indeterminate & left & yes & 8 \\
\hline
\end{tabular}


Table 2

Postoperative rehabilitation protocols

\begin{tabular}{|c|c|c|}
\hline Phase I ( 0 - 2 week) & Phase II ( 2 - 6 week) & Phase III (6-10 week) \\
\hline $\begin{array}{l}\text { - Foot protection in a Cam } \\
\text { Walker Boot } \\
\text { - Walking with the use of elbow } \\
\text { crutches with relief of the } \\
\text { operated limb } \\
\text { - Range of motion exercises } \\
\text { (ROM) including: } \\
\text { metatarsophalangeal joints, } \\
\text { painless ankle joint, knee and hip } \\
\text { joints } \\
\text { - Exercises to activate key muscle } \\
\text { groups of the lower limbs and } \\
\text { central stabilization muscles } \\
\text { - General fitness exercises, e.g. } \\
\text { (stationary bike) } \\
\text { - Antithrombotic prophylaxis } \\
\text { and anti-swelling } \\
\text { (cooling, compression therapy, } \\
\text { e.g. NormaTec, elevation) }\end{array}$ & $\begin{array}{l}\text { - Full lower limb load in a Cam } \\
\text { Walker boot or a shoe } \\
\text { with a hard sole } \\
\text { - Manual therapy including scar } \\
\text { mobilization and manipulation } \\
\text { of soft tissues of the foot and } \\
\text { shank and also foot joints } \\
\text { - Continuation of ROM exercises } \\
\text { - Active and resistance exercises } \\
\text { for the foot and ankle } \\
\text { using resistance tapes } \\
\text { - Exercises to strengthen the } \\
\text { muscles of the lower limbs, the } \\
\text { muscles of the torso and the } \\
\text { upper limbs } \\
\text { - Gait re-education with the use } \\
\text { of an anti-gravity treadmill } \\
\text { - Sensorimotor, stability and } \\
\text { improving exercises } \\
\text { - Rolling, stretching (plantar } \\
\text { fascia, shank muscles) } \\
\text { - Edema prevention }\end{array}$ & $\begin{array}{l}\text { - Full range of motion in the ankle } \\
\text { and foot joints } \\
\text { - Continuation of active and } \\
\text { resistance exercises of the foot and } \\
\text { ankle } \\
\text { - Progressive strength training of } \\
\text { the trunk, lower and upper limbs } \\
\text { muscles } \\
\text { - Progression of sensorimotor and } \\
\text { stability exercises } \\
\text { - General conditioning exercises } \\
\text { (e.g. running on anti-gravity } \\
\text { treadmill) } \\
\text { Progressive training taking into } \\
\text { account the specificity of soccer } \\
\text { and the player position on the } \\
\text { pitch: } \\
\text { - Exercises shaping motor skills } \\
\text { and coordination of the soccer } \\
\text { player } \\
\text { - Plyometric training } \\
\text { - Omni-directional movements } \\
\text { taking into account rotational } \\
\text { moves } \\
\text { - Exercises with the use of a } \\
\text { coordination ladder and cones } \\
\text { - Shuttle run } \\
\text { - Running with different intensity } \\
\text { - Quick response exercises }\end{array}$ \\
\hline
\end{tabular}

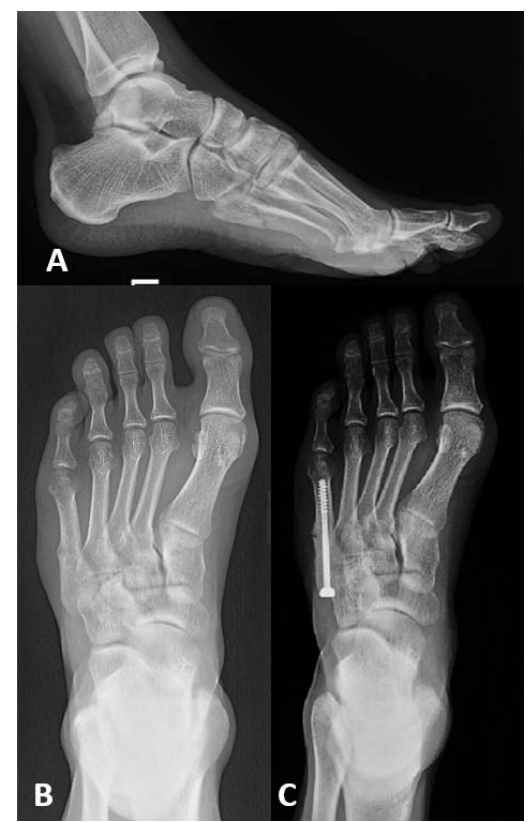

Figure 1

$X$-ray of the fifth metatarsal fracture in left foot in an elite soccer player: A-lateral, before surgery; $B$-anteroposterior, before surgery; C-anteroposterior postoperatively after open reduction 


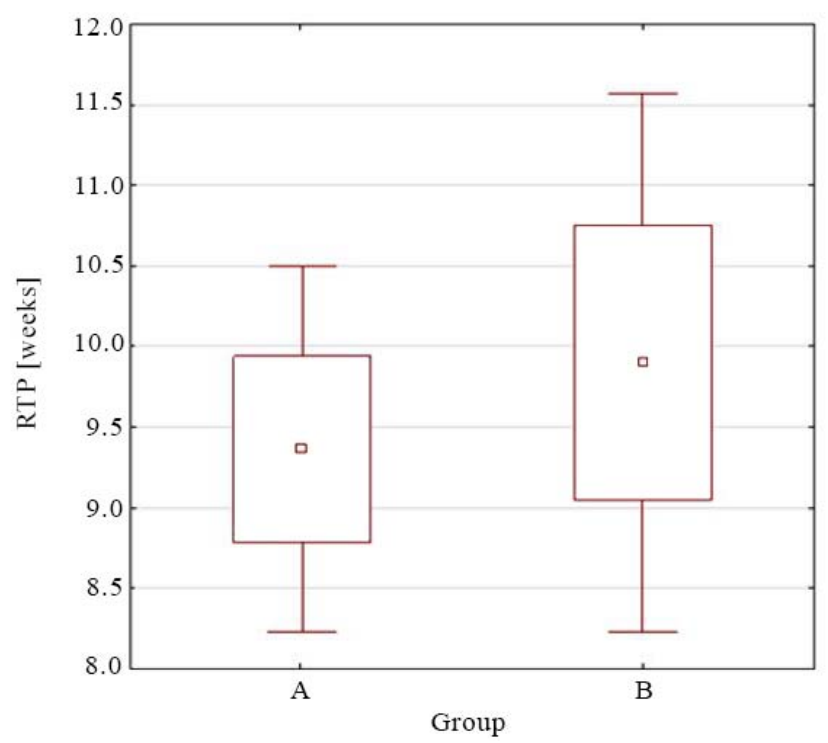

Figure 2

The time needed to return to play after surgical treatment of the fifth bone fracture -

A only surgical treatment players $(n=11),-B$ players with conservative treatment in the past and surgical treatment next $(n=10)(p>0.05)$.

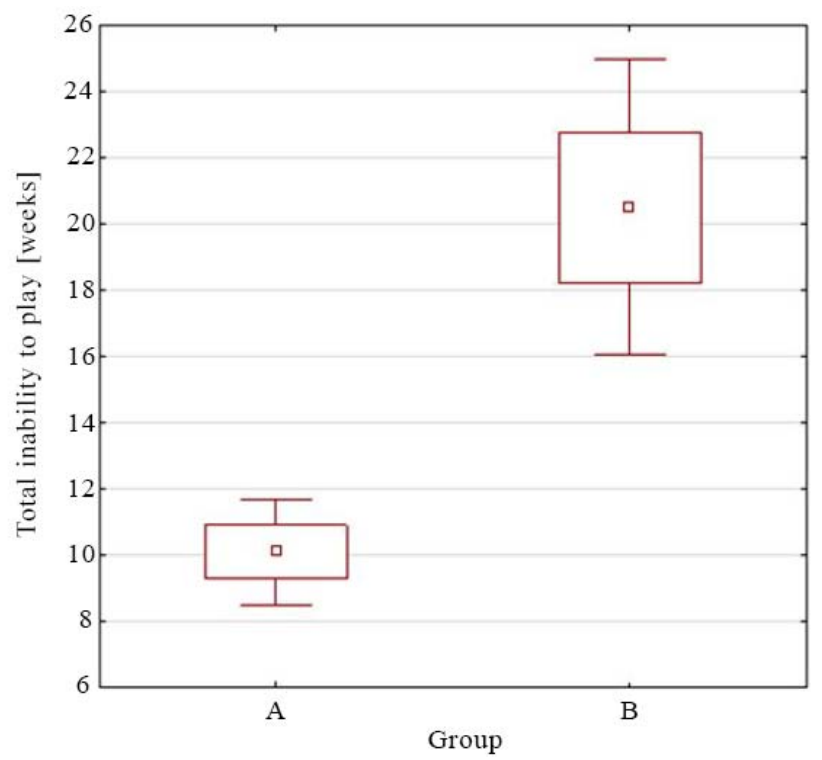

Figure 3

The time of total inability to play after the fifth bone fracture - A only surgical treatment players $(n=11)$,

- B players with conservative treatment in the past and surgical treatment next $(n=10)(p=0.00026)$. 


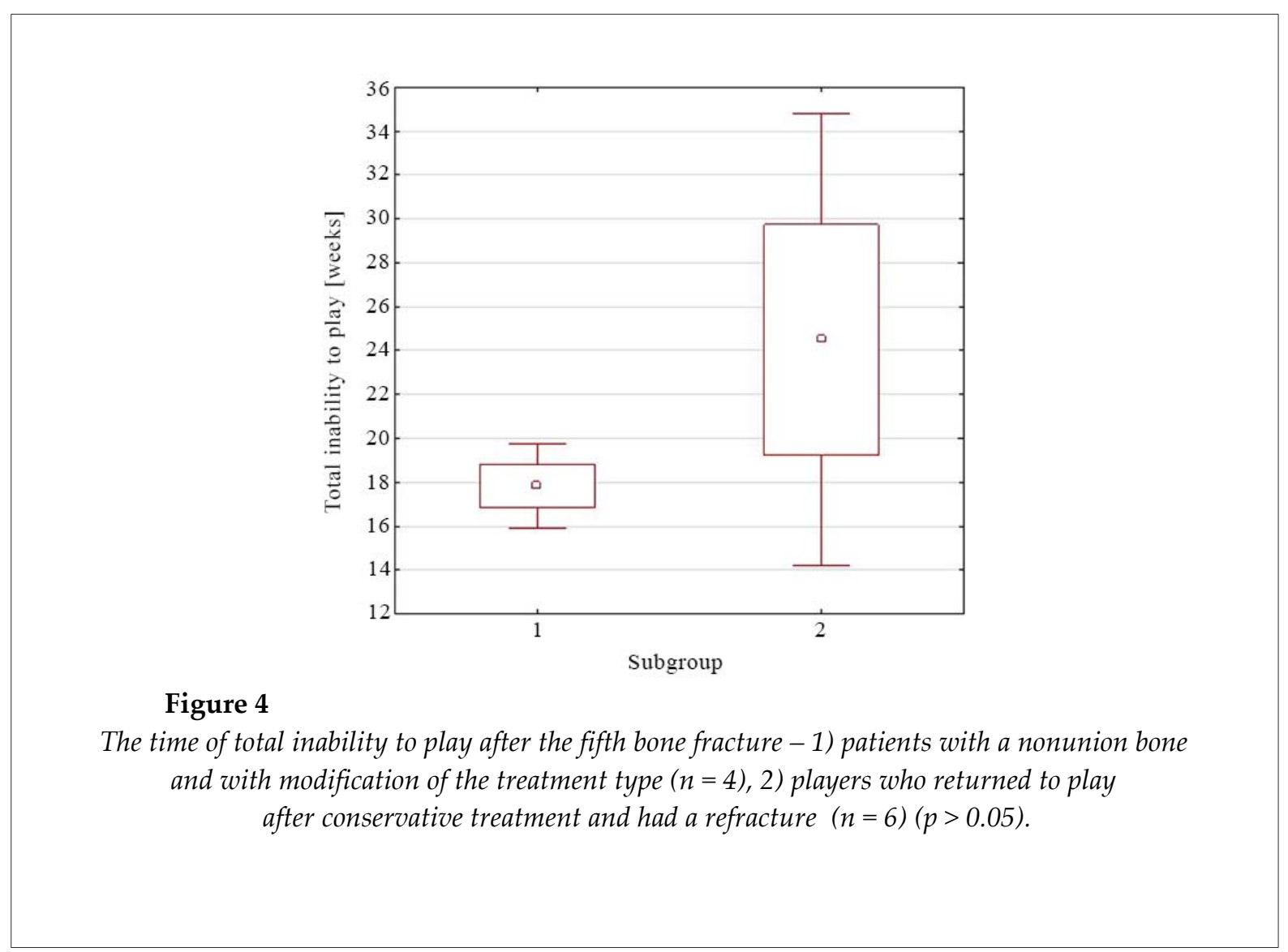

The goal of surgical treatment is anatomical reconstruction of the bone structure, which allows for the correct distribution of influencing forces and the adequate biomechanics of the entire foot to be restored (Kadar et al., 2015). While deciding for surgical treatment, the doctor has a choice between several techniques. These include, among others: intramedullary screw fixation, plate fixation and fixation with Kirschner wire (Baumfeld et al., 2015; Huh et al., 2015). The role of the fixation is to guarantee the stability of the broken bone fragments such that distribution of mechanical stress does not induce deformation in the unification area (Porter et al., 2009). The most commonly used method of fixation is intramedullary screw placement under X-ray control from the proximal side of the 5th metatarsal bone towards the lateral part. This technique enables the recovery of the patient's gait and ability to run within a few weeks after the fixation (Bernstein et al., 2018; Duplantier et al., 2018). A less common solution is a method using Kirschner wire alone, which is the least invasive technique, but at the same time seems to be insufficiently stable, especially in professional athletes (Zwitser and Breederveld, 2010). A plate fixation is characterized by very good endurance and functional performance (Duplantier et al., 2018; Xie et al., 2017). Unfortunately, it is burdened with drawbacks such as a relatively large surgical wound (compared to other methods), the related complications of wound infections and discomfort caused by protruding elements of the plate and screws (Xie et al., 2017). The natural evolution of operational methods from more invasive and less stable to barely invasive and more stable was confirmed by recent reports describing the F.E.R.I. (5th metatarsal, Extra-portal, Rigid, Innovative). It is a synthesis of a stable intramedullary anastomosis with a safe margin of its dynamization. This method seems very promising, yet requires further confirmation of its effectiveness in clinical trials (D'Hooghe et al., 2019). In sports practice, the highest priorities are permanent fusion and comfort of the player's daily function. It is important that the material does not widen the foot contour, which could cause the injured site to become tender while 
having sports shoes on. Hence, most methods rely on intramedullary fracture fixation (Huh et al., 2016) as it seems to be the optimal choice among the available methods (Japjec et al., 2015). External fixation methods in the form of plate or suture cerclage are not very common due to mechanical discomfort (Huh et al., 2016; Mofidi et al., 2009; Sarimo et al., 2006), especially during dynamic activity (Granata et al., 2015; Lee et al., 2011).

A necessary addendum to rehabilitation protocols is properly arranged motor control training, which allows to reduce the likelihood of a refracture. In the fast return to sport after a 5th metatarsal fracture, the early fracture stabilization surgery is recommended for athletes, enabling the implementation of an aggressive rehabilitation protocol as soon as possible. Looney et al. (2020) indicated that early limb loading after surgery (from week 2) did not delay fracture healing, nor hinder the bone union. As a result, it shortened the time of absence from training to a minimum, which is very important for professional athletes (Looney et al., 2020). A helpful tool recommended in the early stages of rehabilitation is the external bone stimulator (e.g. Exogen), which shortens the time of bone regeneration and remodeling (Nolte et al., 2016; Teoh et al., 2018). Implementing early conditioning, gait re-education and subsequent running are possible due to an anti-gravity treadmill (Alter G), which is gaining more popularity in innovative rehabilitation protocols (Thomson et al., 2018). During the last phase of rehabilitation and in the programming of sports training, the player's position on the pitch should be taken into account. According to the researchers' findings, non-linear running accumulates greater forces on the inside foot (Thomson et al., 2018). Performing long passes during the game may significantly increase the loads on the lateral side of the foot. Some authors also report that soccer shoes tend to increase the load born on the foot's sole (Blanchard et al., 2018). After returning to sport, continuous monitoring of the athlete and appropriate management of training loads are recommended, and any pain symptoms should be immediately reported to the medical staff and never be ignored (Kuzuyama et al., 2019; Thomson et al., 2018).

\section{Acknowledgements}

This study would not have been possible without our participants' commitment, time and effort. The study was supported by the laboratory technicians of the Department of Sport and Exercise Sciences (University of Chichester); all authors were involved from the project conception, to manuscript preparation.

\section{References}

Battaglia PJ, Kaeser MA, Kettner NW. Diagnosis and serial sonography of a proximal fifth metatarsal stress fracture. J Chiropr Med, 2013; 12(3): 196-200

Baumbach SF, Prall WC, Kramer M, Braunstein M, Böcker W, Polzer H. Functional treatment for fractures to the base of the 5th metatarsal - influence of fracture location and fracture characteristics. BMC Musculoskelet Disord, 2017; 18(1): 534

Baumfeld D, Macedo BD, Nery C, Esper LE, Filho MA. Anterograde precutaneous treatment of lasser metatarsal fractures: technical description and clinical results. Rev Bras Ortop, 2015; 47(6): 760-4

Bernstein DT, Mitchell RJ, McCulloch PC, Harris JD, Varner KE. Treatment of Proximal Fifth Metatarsal Fractures and Refractures With Plantar Plating in Elite Athletes. Foot Ankle Int, 2018; 39(12): 1410-1415

Blanchard S, Palestri J, Guer JL, Behr M. Current Soccer Footwear, Its Role in Injuries and Potential for Improvement. Sports Med Int Open, 2018; 2(2): E52-E61

Boraczyński M, Boraczyński T, Podstawski R, Wójcik Z, Gronek P. Relationships Between Measures of Functional and Isometric Lower Body Strength, Aerobic Capacity, Anaerobic Power, Sprint and Countermovement Jump Performance in Professional Soccer Players. J Hum Kinet, 2020; 75(4): 161-175

Borghuis J, Hof AL, Lemmink KA. The importance of sensory-motor control in providing core stability: implications for measurement and training. Sports Med, 2008; 38(11): 893-916

Bowes J, Buckley R. Fifth metatarsal fractures and current treatment. World J Orthop, 2016; 7(12): 793-800

D'Hooghe P, Caravelli S, Massimi S, Calder J, Dzendrowskyj P, Zaffagnini S. A novel method for internal fixation of basal fifth metatarsal fracture in athletes: a cadaveric study of the F.E.R.I. technique (Fifth metatarsal, Extra-portal, Rigid, Innovative). J Exp Orthop, 2019; 6(1): 45 
Duplantier NL, Mitchell RJ, Zambrano S, Stone AC, Delgado DA, Lambert BS, Moreno MR, Harris JD, McCulloch PC, Lintner DM, Varner KE. A Biomechanical Comparison of Fifth Metatarsal Jones Fracture Fixation Methods. Am J Sports Med, 2018; 46(5): 1220-1227

Granata JD, Berlet GC, Philbin TM, Jones G, Kaeding CC, Peterson KS. Failed Surgical Management of Acute Proximal Fifth Metatarsal (Jones) Fractures: A Retrospective Case Series and Literature Review. Foot Ankle Spec, 2015; 8(6): 454-459

Hong CC, Nag K, Yeow H, Lin AZ, Tan KJ. Suture Anchor Fixation for Fifth Metatarsal Tuberosity Avulsion Fractures: A Case Series and Review of Literature. J Foot Ankle Surg, 2018; 57(5): 1030-1033

Huh J, Glisson RR, Matsumoto T, Easley ME. Biomechanical Comparison of Intramedullary Screw Versus Low-Profile Plate Fixation of a Jones Fracture. Foot Ankle Int, 2016; 37(4): 411-418

Japjec M, Starešinić M, Starjački M, Žgaljardić I, Štivičić J, Šebečić B. Treatment of proximal fifth metatarsal bone fractures in athletes. Injury, 2015; 46(6): 134-136

Kadar A, Ankory R, Karpf R, Luger E, Elias S. Plate Fixation of Proximal Fifth Metatarsal Fracture. J Am Podiatr Med Assoc, 2015; 105(5): 389-394

Kuzuyama M, Perrier J, Kusaki Y, Sato K, Yamaura I, Tsuchiya A. Characteristics of plantar pressure distribution in elite male soccer players with or without history of proximal fifth metatarsal fracture: a case-control study. J Phys Ther Sci, 2019; 31(7): 530-535

Lawrence SJ, Botte MJ. Jones' fractures and related fractures of the proximal fifth metatarsal. Foot Ankle, 1993; 14(6): 358-65

Lee KT, Park YU, Young KW, Kim JS, Kim JB. Surgical results of 5th metatarsal stress fracture using modified tension band wiring. Knee Surg Sports Traumatol Arthrosc, 2011; 19(5): 853-857

Looney AM, Renehan JR, Dean DM, Murthy A, Sanders TH, Neufeld SK, Cuttica DJ. Rate of Delayed Union With Early Weightbearing Following Intramedullary Screw Fixation of Jones Fractures. Foot \& Ankle International, 2020; 107110072093831

Mayer SW, Joyner PW, Almekinders LC, Parekh SG. Stress fractures of the foot and ankle in athletes. Sports Health, 2014; 6(6): 481-491

Miller D, Marsland D, Jones M, Calder J. Early return to playing professional football following fixation of 5th metatarsal stress fractures may lead to delayed union but does not increase the risk of long-term non-union. Knee Surg Sports Traumatol Arthrosc, 2019; 27(9): 2796-2801

Miyamori T, Nagao M, Sawa R, Tumilty S, Yoshimura M, Saita Y, Ikeda H, Kaneko K. Playing football on artificial turf as a risk factor for fifth metatarsal stress fracture: a retrospective cohort study. BMJ Open, 2019; 9(2): e022864

Mofidi A, Hamer P, Thomas RH, Hemmadi SS. Stress fracture of the fifth metatarsal base caused by tension band wiring: an isolated case report. Foot Ankle Spec, 2009; 2(2): 79-82

Nolte P, Anderson R, Strauss E, Wang Z, Hu L, Xu Z, Steen RG. Heal rate of metatarsal fractures: A propensity-matching study of patients treated with low-intensity pulsed ultrasound (LIPUS) vs. surgical and other treatments. Injury, 2016; 47(11): 2584-2590

Pecina M, Bojanic I, Smoljanovic T, Ivkovic A, Mirkovic M, Jelic M. Surgical treatment of diaphyseal stress fractures of the fifth metatarsal in competitive athletes: long-term follow-up and computerized pedobarographic analysis. J Am Podiatr Med Assoc, 2011; 101(6): 517-22

Porter DA, Rund AM, Dobslaw R, Duncan M. Comparison of 4.5- and 5.5-mm cannulated stainless steel screws for fifth metatarsal Jones fracture fixation. Foot Ankle Int, 2009; 30(1): 27-33

Raikin SM, Slenker N, Ratigan B. The association of a varus hindfoot and fracture of the fifth metatarsal metaphyseal-diaphyseal junction. Am J Sport Med, 2008; 36(7): 1367-1372

Saita Y, Nagao M, Kawasaki T, Kobayashi Y, Kobayashi K, Nakajima H, Takazawa Y, Kaneko K, Ikeda H. Range limitation in hip internal rotation and fifth metatarsal stress fractures (Jones fracture) in professional football players. Knee Sur Spors Traumatol Arthrosc, 2018; 26(7): 1943-1949

Sarimo J, Rantanen J, Orava S, Alanen J. Tension-band wiring for fractures of the fifth metatarsal located in the junction of the proximal metaphysis and diaphysis. Am J Sports Med, 2006; 34(3): 476-480

Teoh KH, Whitham R, Wong JF, Hariharan K. The use of low-intensity pulsed ultrasound in treating delayed union of fifth metatarsal fractures. The Foot, 2018; 35: 52-55 
Thomson A, Akenhead R, Whiteley R, D'Hooghe P, Van Alsenoy K, Bleakley C. Fifth metatarsal stress fracture in elite male football players: an on-field analysis of plantar loading. BMJ Open Sport Exerc Med, 2018; 4(1): e000377

Valkier C, Fallat LM, Jarski R. Conservative Versus Surgical Management of Fifth Metatarsal Avulsion Fractures. J Foot Ankle Surg, 2020; 59(5): 988-992

Wang Y, Gan X, Li K, Ma T, Zhang Y. Comparison of operative and non-operative management of fifth metatarsal base fracture: A meta-analysis. PLoS One, 2020; 15(8): e0237151

Wu G-B, Li B, Yang Y-F. Comparative study of surgical and conservative treatments for fifth metatarsal base avulsion fractures (type I) in young adults or athletes. J Orthop Surg Res, 2018; 26(1): 230949901774712

Xie L, Guo X, Zhang SJ, Fang ZH. Locking compression plate distal ulna hook plate fixation versus intramedullary screw fixation for displaced avulsion fifth Metatarsal Base fractures: a comparative retrospective cohort study. BMC Musculoskelet Disord, 2017; 18(1): 405

Yates J, Feeley I, Sasikumar S, Rattan G, Hannigan A, Sheehan E. Jones fracture of the fifth metatarsal: Is operative intervention justified? A systematic review of the literature and meta-analysis of results. Foot (Edinb), 2015; 25(4): 251-257

Zwitser EW, Breederveld RS. Fractures of the fifth metatarsal; diagnosis and treatment. Injury, 2010; 41(6): $555-562$

\section{Corresponding author:}

\section{Krzysztof Ficek}

Galen-Orthopaedics

Jerzego 6, 43-150 Bieruń, Poland

Phone: +48 785-721-897

Fax: 32/216-44-02

e-mail: krzysztof.ficek@galen.pl 